\title{
Barriers to Business Education: Motivating Adult Learners
}

\author{
Sara B. Kimmel \\ Belhaven College \\ Mary Nell McNeese \\ The University of Southern Mississippi
}

\begin{abstract}
The study compares the responses of 646 adult learners in degree programs from six institutions in the U.S. and Canada to determine statistically significant differences in motivations and barriers to enroll by gender and ethnicity. The students surveyed were enrolled in nontraditional degree programs offered primarily within the context of night classes and accelerated program study in faith-based colleges and one public university, between 2004 - 2005.
\end{abstract}

\section{Introduction}

Bricks and mortar schools are increasingly challenged by students' electronic access to higher education. The addition of more accredited programs to the online delivery system will force colleges and universities to focus recruitment and retention efforts on adult learners who, heretofore, have been a secondary audience for most campuses, despite their current contribution to enrollment numbers and the potential for brand loyalty through their children.

Aging campuses have been something of a curiosity, if not a phenomenon, in the U.S. since the early 1980's. Driven by an increasingly competitive global economy and access to record amounts of student loan funding, adults have flocked to college for academic degrees that they did not attain as traditional undergraduates, citing various reasons, including: the college degree did not seem necessary for success when they were entering job fields at $18-22$ years of age; higher education was not accessible (or practical) to them as traditional undergraduates due to funding, distance, or limited degree offerings; or, the student began, but did not complete, a college degree program as a traditional undergraduate.

Not all adults who did not achieve college degrees as traditional students seek degrees in adulthood. Many are not drawn to college campuses (actual or virtual) by the reasons mentioned earlier. Still others may be interested in attaining a degree, but face numerous barriers that cannot be overcome by personal motivation. This study seeks to provide a framework for understanding the barriers and motivations that exist for adult students by gender and race/ethnicity, recognizing that the true picture cannot be drawn by sampling only those who have overcome barriers to enrollment. The researchers acknowledge that this is a limitation of the current study. 
Several conditions inhibit those who set out to conduct comprehensive studies of adult learners in public and private colleges and universities. Among these are:

(1) lack of access to students currently enrolled and those recruited, but not enrolled; (2) the proprietary nature of enrollment figures in private colleges; (3) the separation of registration from recruitment and marketing to adult learners; and (4) the lack of a national or international database to collect information specifically about adult learners seeking undergraduate and graduate (nondoctoral) degrees.

Findings and commentary from the current study will benefit administrators of non-traditional and accelerated degree programs that market to adult learners and will provide recommendations for program improvement based on the stated needs of the population sample. In addition, the study recommends further research and improvements to the data collection procedures of colleges and universities that have, or plan to have, significant adult student populations.

\section{Literature Review}

Adult enrolment in higher education in the past two decades has provided a boon for North American colleges and universities, and has been a tremendous source of growth for private and faith-based institutions that had historically experienced slow or declining growth prior to 1970 . Despite numerous differentiations for adult learners, researchers agree that the market for adult learners is becoming more competitive, and that institutions seeking to attract adult learners must offer more than simply convenient hours and locations. Encouragement toward degree completion through peer interaction, access to faculty support at convenient hours, and quality of relationships with school administration as cited by Lundberg (2003), could be contributing factors for future success.

Jacobs (1998) examines the "life course transitions" that have provided baselines for studying adult student enrolment, and pays particular attention to delayed school enrolment, suggesting that future growth will not follow the aging trend line that has become apparent in recent years. This being the case, education programs will become more competitive and, as Geiger, Weinstein, and Jones (2004) forecast, "colleges [will] need to revise their programs and curriculum to better fit the needs of these students."

Because several definitions of "adult learner" exist, most studies establish an age and experience baseline at the outset to establish research parameters. The National Center for Education Statistics of the U.S. Department of Education offers the broadest description of adult learner as "adults age 16 or older and not enrolled in the $12^{\text {th }}$ grade or below" (NCES, 2005). Other studies have focused on the tenacity of adult learners and the relationship of admissions test scores to predict college level performance in students 25 years old and older (Hensley \& Kinser, 2001; House \& Keeley, 1996). Lundberg's (2003) study of adult students 30 years old and older, suggests that adult student performance tends to be enhanced by social relationships and that barriers that would be significant to 
younger students are overcome in older students due to advanced time management skills.

The Osgood-Treston (2001) review of studies of adult learners suggests that group members tend to seek or continue in learning environments when they (adults) can adapt easily to the role of student, cope with multiple challenges, and envision themselves as successful over obstacles. For the purpose of this study, adult learners are defined using the Osgood-Treston description of adult learners: age 25 or older with multiple commitments, experience that contributes to their learning, and goals based on well-defined needs. Osgood-Treston further subdivides adult learners into two groups: "those who participate in organized learning activities" (enrichment and community education) and "those who engage in adult learning for academic credit" (p. 3). The current study focuses on the latter group.

Motivation to learn and its positive correlation to student hardiness are examined in the Cole, Field, and Harris study (2004). Adults in non-degree learning programs most frequently participated in work-related courses to maintain or improve skills, to learn new skills, to keep a certificate or license, because their employer required further education, or to receive a promotion or additional pay, but the level of their participation depends on age, income level, experience, and educational level (NCES, 2005).

Gender and ethnic differences have been researched extensively in motivation and performance expectations, including the recent study by Skaalvick and Skaalvick (2004) that focused on gender stereotypes in self-concept in college students. Furthermore, Nellen (2003) emphasizes the need to address adult students' access to campus and professors at times other than office hours, and suggests that technology should be used to promote maximization of in-class time for adult students whose attention spans are low at the end of a long work day. Bell (2003) finds that there are significant differences in "stressors" of college students based on age and gender. The comparison of ethnic and gender differences is detailed by Thornton, Hollenshead, and Larsh (1997) who studied the effect of the measurement device on gender and ethnic differences in motivation to manage.

The need to create shared, participatory experiences for adult learners in hypermedia environments is a conclusion of the Campbell (2004) text. Friga, Bettis, and Sullivan (2003) respond to the substantive forces effecting change in education, particularly MBA institutions, although the enumerated forces are predicted to change the face of education delivery in the $21^{\text {st }}$ century. Among the factors influencing change in education and other industries are globalization, disruptive technologies, demographic shifts, and deregulation, complexities that have contributed to the growth of business degrees as a percentage of all degrees. Grey (2004) adds that business schools in particular must undergo a reinvention process to provide education that offers value to the marketplace 
through "discernible positive effect upon career success (or managerial performance)."

The argument for market driven adult education appears to be supported by business itself. As firms increasingly offer work-life benefits and fully-paid education packages for employees (Sherwood, 2005), adults' expectations from their educational institutions extends beyond the offerings of traditional learning environments to online learning, child and elder care, and grants and scholarships. The current study groups descriptive statistics and examines two factors of demography - gender and race/ethnicity - to inform education administrators in the development of programs for non-traditional adult students.

\section{Hypotheses}

The hypotheses will be used to test the existence of differences by gender and race/ethnicity in motivations and barriers of adult students, and are enumerated as follows:

H1: Adult students will differ significantly by gender in their motivations for seeking education.

$\mathrm{H} 2$ : Adult students will differ significantly by race/ethnicity in their motivations for seeking education.

H3: Adult students will differ significantly by gender in their barriers to higher education.

H4: Adult students will differ significantly by race/ethnicity in their barriers to higher education.

\section{Methodology}

The survey instrument was developed using items of significance noted in the literature review and the responses to open ended questions of cohorts of adult students on two campus locations in Mississippi. One group consisted of undergraduate adults in an accelerated management program. The other group consisted of adult students in a graduate level accelerated business administration program. Each group had spent less than six months in their current program of study, and individuals were believed to offer significant insight into the issues of barriers and motivations. Students in the instrument development groups were asked to list their five most significant motivations for seeking their current degree and their five most significant barriers to attending college for their current degree. Cohorts were advised to record items that they believed had motivated them or acted as barriers, apart from the marketing efforts of their current school.

The resulting questionnaire contained 51 items, including: institutional identification; level of degree and course of study; demographic information, with questions designed using U.S. Census Bureau standards; fifteen motivators to which respondents self-rated using a Likert-style scale; and sixteen barriers to which respondents self-rated using a Likert-style scale. Participants had the 
option of indicating that motivators and barriers were not applicable. The final item was an open-ended question for additional remarks from participants, which queried, "Are there any additional motivations you had or barriers you faced (or currently face) in your decision to enroll in college for the degree you currently seek?"

The survey was administered to 646 students attending five separate faith-based institutions and one public university in four U.S. states and one Canadian province. All of the U.S. programs were located in the southern half of the country. None of the students surveyed were participants in an on-line degree program. The analysis of data was conducted using SPSS.

\section{Findings}

\section{Descriptive Statistics}

The majority (57.58\%) of survey respondents identified themselves as business majors. Related degrees, including accounting, management, marketing, finance, and organizational management accounted for another 162 (25.06\%) responses. The remaining respondents were education, social services, history, speech, and ministry and leadership majors. Approximately $58 \%$ of those surveyed entered their current degree program between the ages of 25-44, with the highest percentage (35.75\%) enrolling between the ages of $25-34$. The average initial age of entry of all students was 31.8 years.

Female respondents (58.20\%) outnumbered males (40.71\%). White respondents made up $52.16 \%$ of those surveyed. Black or African American respondents totaled $37.15 \%$ of the total, and Asian respondents totaled $2.16 \%$.

Hispanic/Latino respondents made up $4.7 \%$ of those surveyed. Less than $1 \%$ of respondents identified themselves as Alaskan or Native American and almost 5\% respondents described their race/ethnicity as "Other".

The highest percentage (30.49\%) of respondents classified their household income as between $\$ 25,000-\$ 49,000$ annually, while $25.85 \%$ earned between $\$ 0$ - \$24,999 annually. Those in the income group $\$ 50,000$ - $\$ 74,999$ household income category made up about $20 \%$ of survey participants. Almost $11 \%$ indicated income of $\$ 75,000-\$ 99,999$. Just over $9 \%$ reported income of $\$ 100,000$ or more.

Some $34 \%$ indicated they have at least one child under age 12 at home, while another $22 \%$ have children between the ages of $12-18$. Of those with children under 12, almost half (47.55\%) also had children between the ages of 12-18. Given these parameters, approximately $46 \%$ of students have care-taking responsibility for minor children. At the same time, 300 adult students $(46.43 \%)$ indicated the existence of a spouse in the home, while 339 (52.4\%) indicated no spouse in the home. About $19 \%$ of those responding have relatives who live with them. Of adult students with children under age 12 in the home, $66 \%$ also have a 
spouse at home. Of those with children under age 12 and no spouse at home, one quarter (24.6\%) have another relative living in the home.

Of the 376 females represented, $140(37.23 \%)$ indicated that they had children under age 12, and $37 \%$ of those with young children also had children 12-18 in the household. Another 39 (10.37\% of total females) had only children over 12 in the home. Correspondingly, of the 263 male respondents, $78(29.65 \%)$ indicated that they had children under age 12 in the home. Of those, $19.23 \%$ also had children 12-18 living in their household. Another 34 (12.92\%) had only children over 12 in the home.

\section{Comparison of Motivations and Barriers (Full Sample)}

While age is not a focus of this study, almost $25 \%$ of those surveyed were ages 24 and younger. It should be noted that motivations vary somewhat when this younger groups of students are removed from the sample. The justification for this approach is suggested by the previous mentioned Osgood-Treston (2001) study, segregating "adult students" as those aged 25 and over.

TABLE 1

FIVE HIGHEST MOTIVATORS, FULL SAMPLE

\begin{tabular}{|c|c|l|c|c|}
\hline Rank & Item \# & \multicolumn{1}{|c|}{ Motivator } & $\mathrm{M}$ \\
\hline 1 & 20 & A desire for personal accomplishment & 3.67 & 645 \\
\hline 2 & 33 & A desire to be a role model for my children & 3.63 & 645 \\
\hline 3 & 21 & $\begin{array}{l}\text { A desire to finish a degree that I began, but did } \\
\text { not complete earlier }\end{array}$ & 3.62 & 645 \\
\hline 4 & 22 & A desire for knowledge/skills in this degree field & 3.47 & 643 \\
\hline 5 & 29 & Encouragement from my children & 3.33 & 644 \\
\hline
\end{tabular}

Table 1 illustrates, using the full sample of respondents, the highest motivators as determined by aggregate mean scores.

TABLE 2

FIVE HIGHEST MOTIVATORS, ADULTS 25 OR OVER

\begin{tabular}{|c|c|l|c|c|}
\hline Rank & Item \# & \multicolumn{1}{|c|}{ Motivator } & $\mathrm{M}$ \\
\hline 1 & 20 & A desire for personal accomplishment & 3.67 & 484 \\
\hline 2 & 21 & $\begin{array}{l}\text { A desire to finish a degree that I began, but did } \\
\text { not complete earlier }\end{array}$ & 3.63 & 484 \\
\hline 3 & 33 & A desire to be a role model to my children & 3.62 & 484 \\
\hline 4 & 22 & A desire for knowledge/skills in this degree field & 3.47 & 483 \\
\hline 5 & 29 & Encouragement from my children & 3.33 & 483 \\
\hline
\end{tabular}

Table 2 illustrates the sample of respondents, excluding students who reported their ages as under 25. 
TABLE 3

FIVE GREATEST BARRIERS, FULL SAMPLE

\begin{tabular}{|c|c|l|c|c|}
\hline Rank & Item \# & \multicolumn{1}{|c|}{ Barrier } & M & $\mathrm{n}$ \\
\hline 1 & 48 & My role as primary caregiver for an elder & 3.01 & 645 \\
\hline 2 & 46 & Lack of childcare for my minor child/children & 2.99 & 645 \\
\hline 3 & 47 & $\begin{array}{l}\text { Lack of funds for childcare for my minor } \\
\text { child/children }\end{array}$ & 2.96 & 645 \\
\hline 4 & 40 & Concern about paying back student loans & 2.68 & 644 \\
\hline 5 & 39 & The lack of personal funds to pay for college & 2.62 & 645 \\
\hline
\end{tabular}

While the top five motivators do not change, degree completion ranks higher with the older age groups than does role modeling for children. At the same time, the five greatest barriers did not vary in rank order between the full sample and the sample excluding those under 25; however, mean scores were slightly higher among adults 25 and over on the two items dealing with funding for college education: student loan payback and personal funds to pay for college. The comparisons are shown in Tables 3 and 4.

The funding scores may reflect a concern among older students that any anticipated salary increase for the degree sought may not be adequate to pay back the student loan. Or the greater concern may simply reflect the knowledge of other financial obligations common to the age group.

TABLE 4

FIVE GREATEST BARRIERS, ADULTS 25 OR OLDER

\begin{tabular}{|c|c|l|c|c|}
\hline Rank & Item \# & \multicolumn{1}{|c|}{ Barrier } & $\mathrm{M}$ \\
\hline 1 & 48 & My role as primary caregiver for an elder & 2.95 & 484 \\
\hline 2 & 46 & Lack of childcare for my minor child/children & 2.93 & 484 \\
\hline 3 & 47 & $\begin{array}{l}\text { Lack of funds for childcare for my minor } \\
\text { child/children }\end{array}$ & 2.91 & 484 \\
\hline 4 & 40 & Concern about paying back student loans & 2.70 & 484 \\
\hline 5 & 39 & The lack of personal funds to pay for college & 2.66 & 484 \\
\hline
\end{tabular}

Comparison of Motivations and Barriers by Gender

Using the sample of 376 females and 263 males, no motivations or barriers of significance by gender were noted. The researchers suggest that a region by region comparison, as the data base is further developed, could be helpful in exposing gender differences. The findings from the current study fail to support $\mathrm{H1}$ : Adult students will differ significantly by gender in their motivations for seeking education. As there were no significant barriers noted by gender, the researchers conclude that the findings also fail to support H3: Adult students will differ significantly by gender in their barriers to higher education. 


\section{Comparison of Motivations and Barriers by Ethnicity}

Ethnicity was compared by using the majority (337 white) responses and combining the minority (240 Black or African American; 32 Other; 14 Asian; and 5 Alaskan Native/Native American) responses to form two comparison groups. One motivator (shown in Table 5) and four barriers (Tables 6-9) were shown to be significant, supporting $\mathrm{H} 2$ : Adult students will differ significantly by race/ethnicity in their motivations for seeking education and $\mathrm{H} 4$ : Adult students will differ significantly by race/ethnicity in their barriers to higher education. As shown in Table 5, minority respondents indicated significantly higher desire for the knowledge and skills offered by the degree field than did majority respondents.

TABLE 5

MOTIVATION SIGNIFICANCE BY RACE/ETHNICITY - DESIRE FOR KNOWLEDGE

\begin{tabular}{|c|l|c|c|c|c|c|c|}
\hline Item \# & \multicolumn{1}{|c|}{ Motivator } & $\mathrm{df}$ & $\mathrm{n}$ & $\mathrm{M}$ & $\mathrm{SD}$ & $t$ & $p$ \\
\hline 22 & $\begin{array}{l}\text { A desire for knowledge/skills in } \\
\text { the field of study }\end{array}$ & 622 & & & & -1.79 & $.04^{*}$ \\
\hline Majority & & 337 & 3.41 & 0.82 & & \\
\hline Minority & & 287 & 3.53 & 0.81 & & \\
\hline
\end{tabular}

*1-tailed

The combination minority group members self reported significantly less confidence in their ability to be successful in matriculation than did the majority students, as illustrated in Table 6.

TABLE 6

BARRIER SIGNIFICANCE BY RACE/ETHNICITY - CONFIDENCE IN ABILITY

\begin{tabular}{|c|l|c|c|c|c|c|c|}
\hline Item \# & \multicolumn{1}{|c|}{ Barrier } & df & $\mathrm{n}$ & $\mathrm{M}$ & $\mathrm{SD}$ & $t$ & $p$ \\
\hline 35 & $\begin{array}{l}\text { A lack of confidence in my } \\
\text { ability }\end{array}$ & 624 & & & & -1.81 & $.04^{*}$ \\
\hline Majority & & 337 & 1.98 & 1.15 & & \\
\hline Minority & & 289 & 2.15 & 1.23 & & \\
\hline
\end{tabular}

*1-tailed

As Table 7 shows, time away from the job to attend college classes posed a greater barrier for majority students than it did for minority students. Majority adult students were significantly more likely to cite lack of childcare for a minor child or children as a barrier to seeking higher education, as detailed in Table 8. Interestingly, just $28.18 \%$ of majority students reported having one or more children under the age of 12 living in the home, while $39.86 \%$ of minority students reported having one or more children below the age of 12 in the home. Of majority students reporting, $11.57 \%$ had only children ages $12-18$; whereas, $9.2 \%$ of minority students had children ages $12-18$ only. 
TABLE 7

BARRIER SIGNIFICANCE BY RACE/ETHNICITY - TIME AWAY FROM JOB

\begin{tabular}{|c|c|c|c|c|c|c|c|}
\hline Item \# & Barrier & $\mathrm{df}$ & $\mathrm{n}$ & $\mathrm{M}$ & $\mathrm{SD}$ & $t$ & $p$ \\
\hline 44 & Time away from my job & 623 & & & & & \\
& & & & & & \\
\hline & Majority & & 337 & 2.44 & 1.38 & & $.04^{*}$ \\
\hline Minority & & 288 & 2.24 & 1.43 & & \\
\hline
\end{tabular}

*1-tailed

TABLE 8

BARRIER SIGNIFICANCE BY RACE/ETHNICITY - LACK OF CHILDCARE

\begin{tabular}{|c|l|c|c|c|c|c|c|}
\hline Item \# & \multicolumn{1}{|c|}{ Barrier } & $\mathrm{df}$ & $\mathrm{n}$ & $\mathrm{M}$ & $\mathrm{SD}$ & $t$ & $p$ \\
\hline 46 & $\begin{array}{l}\text { Lack of childcare for minor } \\
\text { child/children }\end{array}$ & 617 & & & & 2.57 & $.05^{\star}$ \\
\hline Majority & & 337 & 3.15 & 1.70 & & \\
\hline Minority & & 289 & 2.81 & 1.67 & & \\
\hline
\end{tabular}

*1-tailed

Majority white adult students were also significantly more likely than minority students to report that acting as primary caregiver for an aging family member was a barrier to enrollment. This finding is shown in Table 9.

TABLE 9

BARRIER SIGNIFICANCE BY RACE/ETHNICITY - CAREGIVER FOR ELDER

\begin{tabular}{|c|c|c|c|c|c|c|c|}
\hline Item \# & Motivator & $\mathrm{df}$ & $\mathrm{n}$ & $\mathrm{M}$ & $\mathrm{SD}$ & $t$ & $p$ \\
\hline 48 & Primary caregiver for elder & & & & & & \\
& & 624 & & & & 1.68 & $.05^{\star}$ \\
\hline Majority & & 337 & 3.10 & 1.76 & & \\
\hline Minority & & 289 & 2.87 & 1.74 & & \\
\hline
\end{tabular}

*1-tailed

\section{Discussion}

The study finds that adult learners in undergraduate programs are often those with some college experience, but lacking a four-year degree, and motivated by a desire for personal accomplishment and completion of a previously set goal. While adult learners in all degree programs are often believed to be highly motivated to return to college for employment promotion requirements, pay scale benchmarks, career change, or attainment of management position, intrinsic benefits appear to be greater motivators for the sample group studied. The role of minor children in the decision to attend college should not be disregarded, as it is something of a "Catch-22" for parents. Adult learners recognize the competitive value of a college education and seek to emphasize this to their own children by 
acting as role models, but may not be able to find or afford childcare so they can attend classes.

Barriers were not expected to be significant for the population surveyed (adults enrolled in nontraditional education), as barriers have been overcome or did not exist for many of those who responded; however, descriptive statistics reveal that having a primary caregiver role for minor children and elders, coupled with lack of funds for childcare and concern about paying back student loans are worrisome factors for adults in the decision to return to college.

The lack of statistically significant differences by gender on items of motivation or barriers in the current sample group fails to support the related hypotheses, but is revealing nonetheless. Although the current study did not closely analyze the compound effect of gender and age, a previous analysis using a sample of some 400 students in the southern region of the U.S. revealed gender distinctions by age, suggesting that barriers become more significant to females as they age. The correlation needs more study.

Differences in motivations and barriers noted between groups by race suggest that institutions can do more to serve ethnic populations. Minority students reported significantly higher motivation than those in the majority to gain knowledge and skills in the degree program, but were significantly less confident in their own abilities than were majority students. This extends the Campbell (2004) conclusion in favor of participatory groups beyond hypermedia and into mentoring and supportive educational group environments. At the same time, majority students noted significantly higher barriers than did majority students in time away from work, lack of childcare, and primary role as caregiver to an elder than did minority students.

It should also be pointed out that none of the barriers noted by students as significant fall into the "quick fix" category. Indeed, motivation and confidence are based in a shared cultural experience and are generally considered to be ingrained as a part of the individual's schema (Bem,1985). Some colleges and universities offer some form of assistance to students through institutionalized child care or elder care; however, these services are not customarily considered by administrators to be within the realm of the college educational experience and are often viewed as creating greater liability for the institution.

Assuming equal societal and institutional access to dependent care services, the child and elder care responses appear to suggest that minority students have a supportive domestic or extended family environment that is not available in the same measure to majority students.

Apart from supporting the convenience attraction of on-line degree programs, these findings seem to point institutions toward planning for alternative class delivery formats, times, and media. This is not to suggest that the "on-campus" experience is a thing of the past. To the contrary, the findings indicate that 
colleges and universities can thrive in the adult market by creatively addressing the barriers that adult students face. Administrators should consider reasonable options, such as: hybrid delivery programs that include "face time" and online learning; solid opportunities for adult minority mentoring; strong team experiences and team training; and, partnerships with new or existing child and elder care facilities.

\section{Future Research}

The researchers continue to seek partnering college and university researchers to expand the database of adult learners with the goal of sharing knowledge with the academic community about the adults being served in non traditional programs. Future studies will explore the relationships among gender, age, and ethnicity, and will focus on internationalizing the project.

\section{References}

Bell, J. (2003). Statistics Anxiety: The Non-traditional Student. Education, V124I1,157 (6).

Bem, S. (1985) Androgeny \& Gender Schema Theory: A Conceptual \& Empirical Integration," In Psychology \& Gender, Nebraska Symposium on Motivation 1984, Ed. By Theo B. Songderegger, Lincoln, NE: University of Nebraska Press, 179226.

Campbell, K. (2004) From Text to e-Text-Message Design. In E-ffective Writing for e-Learning Environments. ed. Hershey, PA: Information Science Publishing.

Cole, M. S., Field, H.S. \& Harris, S.G. (2004). Student Learning Motivation and Psychological Hardiness: Interactive Effects on Students' Reactions to a Management Class. Learning \& Education, 3(1), 64.

Geiger, J. F., Weinstein, L. \& Jones. C.S. (2004). Differences in Meaning in Life in Students: the Effect of Nontraditional Status and Region of Country. College Student Journal,V38I4, 569(4).

Grey, C. (2004). Reinventing Business Schools: The Contribution of Critical Management Education. Academy of Management Learning and Education, V3N2, 178(8).

Hensley, L. G. \& Kinser, K. (2001) Perspectives of Adult Learners on Returning to College: A Study of Tenacious Persisters. Academic Exchange Quarterly, V5I12,181.

House, J. D. \& Keeley, E.J. (1996). Differential Prediction of Adult Student Performance from Miller Analogies Test Scores. Journal of Genetic Pyschology, V157N4, 3. 
Jacobs, J. A. \& Stoner-Eby, S. (1998). Adult Enrolment and Educational Attainment. The Annals of the American Academy of Political and Social Science, V559P91, 18.

Lundberg, C.A. (2003). The Influence of Time - Limitations, Faculty, and Peer Relationships on Adult Student Learning: A Causal Model. Journal of Higher Education, V7416, 665(24).

NCES National Center for Education Statistics. (2005) Reasons for Adults' Participation in Work-related Courses, 2002-2003. U.S. Department of Education Institute of Education Sciences. NCES 2005-088, 1(5).

Nellen, A. (2003). Using Technology to Teach Nontraditional Students. The Tax Adviser, V34l5, 290(3).

Osgood-Treston, B. (2001). Program Completion Barriers Faced by Adult Learners in Higher Education. Academic Exchange Quarterly,V5I2,120.

Sherwood, S. (2005) Who Is A Successful Woman? Diversitylnc, 52(5).

Skaalvick, S. \& Skaalvick, E. (2004). Gender Differences in Math and Verbal Self-Concept, Performance Expectations, and Motivation. Sex Roles: A Journal of Research, V5013-4, 241(12).

Thornton, G. C., Hollenshead, J.D. \& Larsh, S.L. (1997). Comparison of Two Measures of Motivation to Manage: Ethnic and Gender Differences. Educational and Psychological Measurement, V57N2, 241(13). 